\title{
Pro AND CONS OF TARGETED SELECTIVE TREATMENT AGAINST DIGESTIVE-TRACT STRONGYLES OF RUMINANTS
}

\author{
CABARET J.*
}

\section{Summary:}

The increasing prevalence of resistance to anthelmintics among gastrointestinal nematodes and the desire for lower input agriculture have promoted the idea that targeted selective treatment (treating the animals in need of such a treatment and only them) could be a sustainable solution for controlling internal parasites of ruminants. The pros are the slowing of resistance prevalence, lower residues of anthelmintics in meat and milk, and lower cost; the cons are the difficulty and time spent on selecting animals in need of treatment and the possibility of lower production. Using actual experiments and modelling we show that targeted selective treatment can be used to sustainably control gastrointestinal nematode infections in flock.

KEY WORDS : anthelmintic, treatment, resistance, targeted selective treatment, ruminant.

$\longrightarrow$ ontrol of gastrointestinal strongyles (Trichostrongylid nematodes) has been a subject of debate for many decades. Their life cycle is direct (ruminants become infected by ingesting infective larvae on the herbage, they subsequently pass eggs in their faeces, developing into infective larvae and migrating onto the grass). They are detrimental to their hosts, through diarrhoea, anaemia, and impaired digestive assimilation, depending on the species involved. Extensification and a higher percentage of herbage in the food of ruminants will increase the importance of gastrointestinal strongyles. Farmers were inclined to treat their animals at regular intervals since several drugs were relatively cheap and highly effective. The appearance of resistance to one of several type of drugs, of one or several nematode species in many countries (see Cabaret, 2000 among others), questioned the strategy of systematic treatment on a regular basis. It is well known that the increasing number of treatments increases the probability of appearance of resistance and its spreading (Silvestre et al., 2002). The necessity of a decent income for farmers and the emotional demands of food consumers for quality food (healthy for themselves and free of chemical residues) and welfare of animals that provide this food, makes the control of gastrointestinal strongyles difficult. The usual

* INRA, IASP, 213, Resistance and Virulence, 37380 Nouzilly, France. Fax: 33 (0)2 47427774 - E-mail: cabaret@tours.inra.fr control of gastrointestinal strongyles (treat as much as you want) is no more a sustainable position. There are some techniques based on paddocks'use for controlling parasites (Barger, 1997), such as: i) preventive grazing management-delayed turn-out, change of pastures between seasons, and the use of more aftermath; ii) diluting grazing management - mixed or alternate grazing with other host species; iii) evasive grazing pasture management like changing the pasture within the season; iv) supplementary feeding in the spring. The pasture management is fairly complex and most farmers rely on the sole treatments. Targeted selective treatment strategy (TST) is also complex: how can we detect the animals in need for treatment? When should we treat? How can we combine the control through optimal use of paddocks and targeted selective treatment of ruminants? The limited use of anthelmintic treatments is not a simple proposal (Cabaret, 2007) and it includes high level of technicity.

\section{INDIVIDUATION OF PARASITIC INFECTION: ON WHICH BASIS?}

\section{DiReCt EVALUATION}

1 the most obvious is faecal egg counts (eggs per gram-EPG) and it has been largely used for managing control of digestive-tract strongyles since the 1920s. The idea is that faecal egg counts may be related to actual infection. The statement is true when groups of animals are evaluated (in sheep and goats: Cabaret et al., 1998; in young cattle: Suarez, 1997). It is much less realistic when individual evaluation is expected. The young cattle and sheep data are presented in Figure 1; the Spearman rank correlation ranged from 0.60 to 0.70 , which means that 36 to $49 \%$ of worm number variance is explained by faecal egg counts. It can be easily seen, in the two proposed examples, that treatment based on EPG values will not identify exactly the animals in need of treatments: $i$ ) in young cattle only four (out of 65) very high epg identify hosts with very infection (over 100,000 worms, 
which probably may be identified by other means); ii) in sheep three highly (out of 45) infected animals are easily detected by high EPG whereas one would be treated without a real necessity. Bishop \& Stear (2000) used a gamma-type function to assess the relationship between adult Teladorsagia circumcincta and egg output. The individual relationship was good at low and medium level of infection, whereas it was poor for high infections. The adjusted distributions (negative binomial, gamma, or Weibull- distributions,
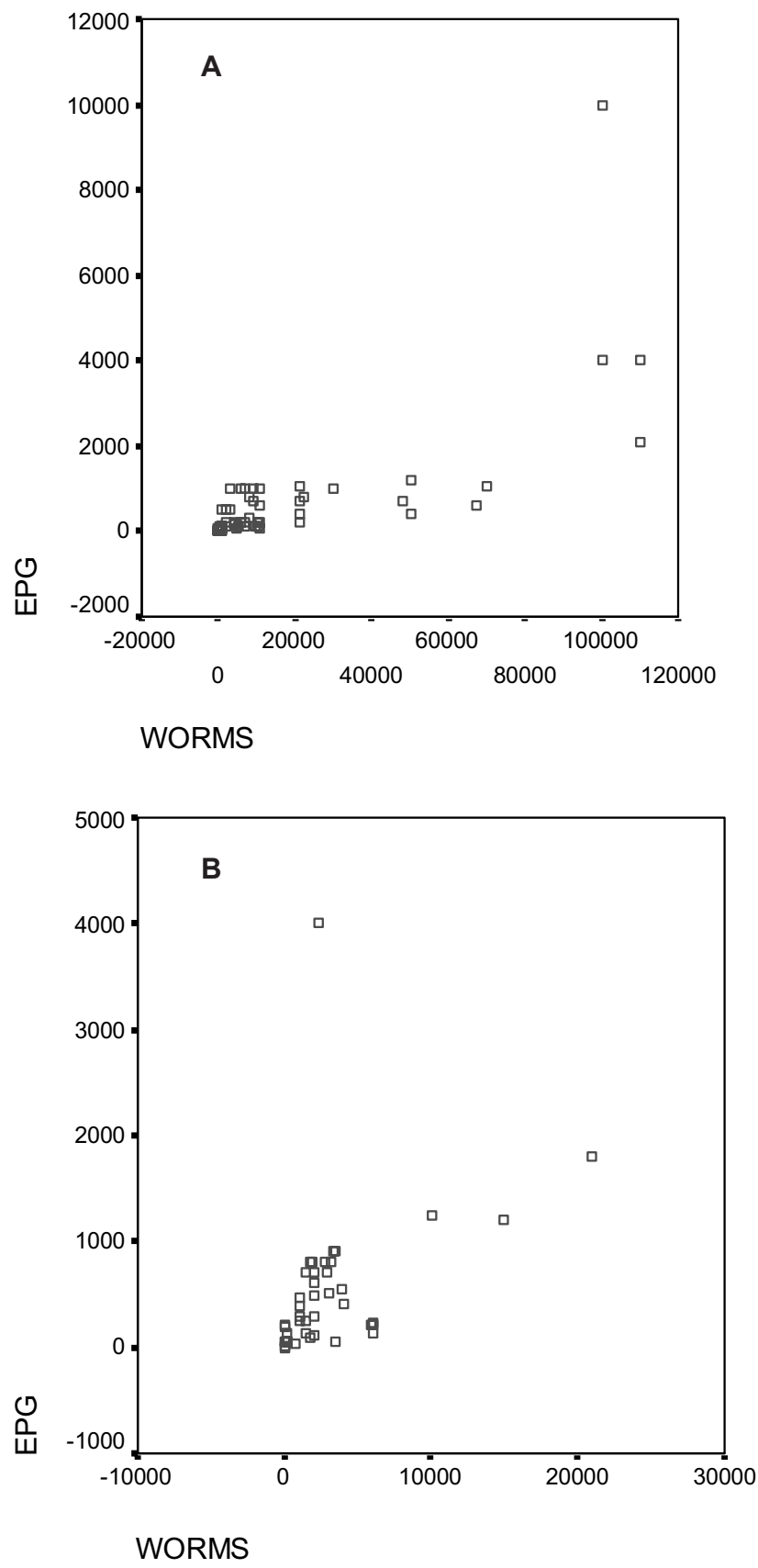

Fig. 1. - Relationship between egg per gramme and actual worm burden in young cattle (less than 12 months old: reinterpreted from Suarez, 1997-A) and sheep and goats (reinterpreted from Cabaret et al., 1998-B).
Gaba et al., 2005) were investigated mostly because poor adequation between epg and number of worms was recorded among the most infested hosts. It means plainly that the most infected hosts are somewhat unpredictable from two points of view: a theoretic one (distribution of parasites) and a more applied one, based on how to detect highly infected hosts. However a strategy of treatment based on epg could be successfull at the group level as shown in the next paragraph.

\section{INDIRECT EVALUATIONS}

The Famacha ${ }^{\odot}$ system based on clinical anaemia has been used extensively in South Africa for detecting sheep infected with Haemonchus contortus (Wyk \& Bath, 2002). It is common knowledge that during the course of fatal haemonchosis the colour of the conjunctiva changes from the deep red of healthy sheep, through shades of pink to practically white, as a result of worsening anaemia. The changes of colour are correlated with pack cell volume-PCV (Pearson correlation: $r^{2}=0.34$ to 0.49$)$. The decision to treat was correct in 89 to $95 \%$ of animals (cut-off being < 15 PCV). The reduction in the number of treatments was 38-80\% depending on farm in South Africa. Only $30 \%$ of the sheep could not cope with the worm challenge without at least one treatment. The Famacha ${ }^{\odot}$ sytem is of interest when $H$. contortus, a blood sucker worm, is the main digestive-tract strongyle, which is the case in many tropical countries (see Mahieu et al., 2007). The interpretation is complicated when other haematophagous pathogens are present. The results are not as good under temperate climate as shown by Koopman et al. (2006) in sheep and goats.

Dag score (Larsen et al., 1995) has been used in Australia to detect sheep in need of treatment against digestive-tract strongyles. It is indicative of repeated diarrhoea, and was found to be repeatable: the same lambs were detected for dag score along the grazing season. The Diarrhoea score (DISCO, Cabaret et al., 2006) is based on the dry-matter of faeces at the moment of examination (particularly when preparing faeces for faecal egg counts). It is not repeatable and is indicative of diarrhoea at one moment of the life of the lamb and is thus different from dag score. The score of 1 correspond to normal sheep faeces in pellets, 2 is for "soft" faeces (similar to cow pat) and 3 is for diarrhoea (semi-liquid faeces). These scores correspond to 40, 26 and $16 \%$ dry-matter. The number of digestive tract-strongyles worms was much higher in the diarrhoea group (Teladorsagia circumcincta $\times 4$, Trichostrongylus axei $\times 5$, Nematodirus $\times 4$ ) in beginning of summer necropsied lambs from AuvergneFrance. The difference was more important for larval stages of T. circumcincta $(\times 10)$ or Nematodirus (only 


\begin{tabular}{lcccc}
\hline \multicolumn{1}{c}{ Parasite } & $\begin{array}{c}\text { Early } \\
\text { spring }\end{array}$ & $\begin{array}{c}\text { Late } \\
\text { spring }\end{array}$ & Summer & Autumn \\
\hline Coccidia & + & NS & NS & NS \\
Digestive tract strongyles & NS* & + & NS & + \\
Nematodirus & NS & $?$ & NS & NS \\
Strongyloides & NS & NS & + & + \\
Moniezia & NS & + & NS & NS \\
\hline
\end{tabular}

* non significant relationship.

Table I. - Associations of Disco 3 (Diarrhoea) and internal parasites of lambs along the year in semi-montane climate (Auvergne-France) (modified of Cabaret et al., 2006).

present in diarrhoea group). Interpretation of Disco depends on the period of the year (Table I): Coccidia protozoa are probably the cause of diarrhoea in early spring, then digestive-tract strongyles and the cestode Moniezia, and then digestive-tract strongyles and Strongyloides in autumn. It cannot be used in farms where no information on internal parasites is available and association of DISCO with faecal examination for parasites is recommended.

Weighing with electronic scale may give information on the animal with low resilience for internal parasites. However it is not specific of parasitic infection and may depend on food availability. Weigh band could be used but individual accuracy is poor and it cannot be considered as a tool for individual decision.

\section{FLOCK/HERD RECOMMENDATIONS BASED ON A COMBINATION OF INDICES}

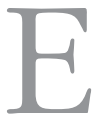
ach of the reviewed indices (faecal egg counts, Famacha $^{\odot}$, Disco, Weight gains) has its own limitations and one may think that a combination of indices should prove more efficient in detecting the animals in need to be treated.

Costa et al. (1989) in the Argentina Pampa did show that in young cattle, the combination of faecal egg counts and daily weight gains was efficient in reducing the number of treatments from eight to two or three in cattle fattened on grass from six month to 18 months. Ten young cattle were sampled monthly at random and the decision for treatment was based on negative/nil or low weight gains associated with faecal egg counts over 300.

A combination of Famacha ${ }^{\circ}$ (3 and over), Disco (Disco 3) and weight gains (negative) was used in lambs grazed on experimental paddocks in French Touraine (Cabaret et al., 2006) experimentally seeded with partly benzimidazole resistant worms (proportion in the initial community: Teladorsagia circumcincta $60 \%$, Trichostrongylus colubriformis $30 \%$, Haemonchus contortus $10 \%$ ). A single index with the above level was a necessary condition for treatment. The most efficient was weight gains. The number of treatments was half in the TST group compared with the monthly treated group. Productivity ( 42 to $43 \mathrm{~kg}$ body weight) and resistance to benzimidazoles ( 45 to $65 \%$ efficacy) were at the same level at the end of the grazing season. Thus, the use of principally weight gains was efficient in reducing the number of treatments.

The combination of indices, although feasible, is time consuming and we should not expect farmers in temperate areas, with high labour cost, to test each lamb monthly. There is a real difficulty for farmers to accept TST-due to overwork and also lack of decision guide for treatment (Wok et al., 2006). In centre France, meat sheep flocks range from 500 to 1,000 ewes (Beloit \& Montaigne, 2002), and they are fed, treated, set to reproduction programs by one permanent person with occasional help, and it is not possible to ask for further work dedicated to individual treatments. What one may imagine is that, like in the cattle example, several sentinels (10 lambs, not the same each month in order to avoid the difficulty to select the same lambs each month) are sampled for faeces-faecal egg counts and Disco, and Famacha ${ }^{\odot}$. According to the results, decision of treating all lambs could be taken or not. Decision making is fairly complex, and we still have no general rules for building a decision tree. Modelling, using realistic individually-based model, may help to explore the evolution of gastrointestinal intensity and resistance to treatments (Gaza et al., 2006). Thus it was found that treatments in the summer may select for resistance in Teladorsagia circumcincta. The high stocking rates were also a force in promoting resistance.

\section{FLOCK/HERD RECOMMENDATIONS BASED ON SUSCEPTIBILITY OF A CATEGORY AT RISK}

Tr $\mathrm{t}$ is current knowledge that young ruminants are more susceptible to most of the internal parasites. This is particularly true in cattle where cows are very lightly infected and thus only young cattle is usually treated (Vercruysse \& Clarebout, 2001). In sheep, lambs are frequently treated (up to once a month) whereas ewes are treated two or three times a year in temperate climates. Dairy goats are highly susceptible to digestive tract strongyles, and highly productive goats are even more susceptible (Hoste et al., 2002). It has been shown in experimental infection, during the first three months of lactation, that milk yield in high producers was reduced by $18 \%$ whereas in the rest of the flock the reduction was $6 \%$. The treatment of high producers only may leave untreated 33 to $55 \%$ of the goats without detrimental effect on milk production (Hoste et al., 2002). 


\section{CONCLUSIONS}

T argeted selective treatment is an attractive proposal as an abstraction: only animals in need are treated. It is thus reducing residues in meat products, it controls the spreading of resistance to anthelmintics, and permits control of digestive tract infection. The drawbacks are the necessity to evaluate infection and pathology along the grazing season on numerous animal hosts. The decision to treat remains complex and modelling/decision tree are necessary tools for developing efficient treatment strategies.

\section{ACKNOWLEDGEMENTS}

he discussion with colleagues within European Program Parasol has been stimulating for constructing this review. The financial help of European Union (Parasol) and Prad (Morocco-France bilateral program) is gratefully acknowledged.

\section{REFERENCES}

BARGER I.A. Control by management. Veterinary Parasitology, 1997, 72, 493-506.

Benoit M. \& LAIGNel G. Constraints under organic farming on French sheepmeat productions: a legal and economic point of view with an emphasis on farming systems and veterinary aspects. Veterinary Research, 2002, 33, 613-624.

Bishop S.C. \& STEAR M.J. The use of a gamma-type function to assess the relationship between the number of adult Teladorsagia circumcincta and total output. Parasitology, 2000, 121, 435-440.

CABARET J. Anthelmintic resistance in goats: from fiction to factsin. Proceedings of the $7^{\text {th }}$ International Conference on Goats, Tours-Poitiers, France, 15-18 May 2000, 793-794.

CABARET J. Practical recommendations on the control of helminth parasites in organic sheep production system. CAB Reviews: Perspectives in Agriculture, Veterinary Science, Nutrition and Natural Resources, 2007, 2, 1-7.

Cabaret J., Gasnier N. \& JacQuiet P. Faecal egg counts are representative of digestive-tract strongyle worm burdens in sheep and goats. Parasite, 1998, 5, 137-142.

Cabaret J., Gonnord V., Cortet J., Sauvé C., Ballet J., TourNADRE H. \& BENOIT M. Indicators for internal parasitic infections in organic flocks: the diarrhoea score (Disco) proposal for lambs. Organic Congress 2006: Organic Farming and European Rural Development. Odense DK, 3031 May 2006, 552-553.

Cabaret J., Silvestre A., Cortet J. \& Sauve C. Nematode targeted selective treatments in lambs under temperate climate using weight gains, anaemia or diarrhoea scores. ICOPA XI- $11^{\text {th }}$ International Congress of Parasitology. Glasgow (UK), 6-11 August 2006.

Costa J., Mejia M., Martinez E.F. \& Cabaret J. El control de la gastroenteritis verminosa en la Pampa húmeda (Argen- tina) bajo condiciones de campo, entre 1979 y 1987: resultados. Technicrea, 1989, 3-17.

Gaba S., Cabaret J., Ginot V. \& Silvestre A. The early drug selection of nematodes to anthelmintics: stochastic transmission and population in refuge. Parasitology, 2006, 133, 345-356.

Gaba S., Ginot V. \& Cabaret J. Modelling macroparasite aggregation using a nematode-sheep system: the Weibull distribution as an alternative to the Negative Binomial distribution? Parasitology, 2005, 131, 393-401.

Hoste H., Chartier C. \& Le Frileux Y. Control of gastrointestinal parasitism with nematodes in dairy goats by treating the host category at risk. Veterinary Research, 2002, $33,531-545$.

Koopmann R., Holst C. \& Epe C. Experiences with the FAMACHA (c)-Eye-Colour-Chart for identifying sheep and goats for targeted anthelmintic treatment. Berliner und Münchener Tierärztliche Wochenschrift, 2006, 119, 436442.

Larsen J.W.A., Vizard A.L., WebB-Ware J.K. \& Anderson N. Production losses in Merino ewes and financial penalties caused by trichostrongylid infections during winter and spring. Australian Veterinary Journal, 1995, 72, 196-197.

Mahieu M., Arquet R, Kandassamy T., Mandonnet N. \& Hoste H. Evaluation of targeted drenching using Famacha ${ }^{\odot}$ method in Creole goat: reduction of anthelmintic use, and effects on kid production and pasture contamination. Veterinary Parasitology, 2007, 146, 135-147.

Silvestre A., Leignel V., Berrag B., Gasnier N., Humbert J.F., Chartier C. \& CABaret J. Sheep and goat nematode resistance to anthelminthics: pro and cons among breeding management factors. Veterinary Research, 2002, 33, 465480.

SuAREZ V. Diagnostico de las parasitosis internas de los rumiantes en la region de invernada. Interpretacion y tecnicas. INTA, Anguil (Argentina). Boletin de divulgacion Tecnica No 56, 1997, 50 p.

VERCRUYSSE J. \& ClAEREBOUT E. Treatment versus non treatment of helminth infection in cattle: defining the threshold. Veterinary Parasitology, 2001, 98,195-214.

Wyk van J.A., Hoste H., Kaplan R.M. \& Besier R.B. Targeted selective treatment for worm management - How do we sell rational programs to farmers? Veterinary Parasitology, 2006, 336-346.

WYK VAN J. \& BATH G. The FAMACHA ${ }^{\odot}$ system for managing haemonchosis in sheep and goats by clinically identifying individual animals for treatment. Veterinary Research, 2002, 33, 509-522. 